\title{
EL CLERO CATEDRALICIO LEONÉS EN LA EDAD MODERNA: LOS CANÓNIGOS, DIMENSIÓN Y SOCIOLOGÍA DE UNA ELITE SOCIAL*
}

\author{
POR \\ MARÍA JosÉ PÉREZ ÁlVAREZ ${ }^{1}$ \\ Universidad de León
}

\section{RESUMEN}

El cabildo de la catedral de León, fundado en la Edad Media, fue estudiado por algunos autores desde diversas vertientes, entre la que cabe destacar la económica y legislativa. En este trabajo nos proponemos ofrecer una visión bien distinta, pues el análisis estará centrado en sus miembros, y más concretamente en las dignidades, oficios y prebendados. Se trata de una primera aproximación a la sociología de sus integrantes: procedencia social, redes clientelares o algunas variables demográficas, tales como la edad a la que ingresan en el mismo o la de fallecimiento.

PALABRAS CLAVES: Edad Moderna; León; clero; cabildo catedralicio; canónigos.

\section{CATHEDRAL CLERGY IN LEÓN IN THE EARLY MODERN PERIOD: THE CANONS, DIMENSION AND SOCIOLOGY OF SOCIAL ELITE}

\begin{abstract}
Various facets of the chapter of the Cathedral of León, founded in the Middle Ages, have been studied, including economic and legislative aspects. The aim of the present study was to examine a very different angle, focusing on the members themselves, and more specifically on the deans, officers and prebendaries. This represents an initial exploration of the sociology of the chapter members: their social background, patronage networks and demographic variables such as age on entering the chapter or at death.
\end{abstract}

KEY WORDS: Early Modern Period; León; clergy; cathedral chapter; canons.

Cómo CITAR ESTE ARTículo / CITATION: Pérez Álvarez, M.a J. 2018. «El clero catedralicio leonés en la Edad Moderna: los canónigos, dimensión y sociología de una elite social». Hispania Sacra 70, 142: 509-523. https://doi.org/10.3989/hs.2018.035

Recibido/Received 23-06-2016

Aceptado/Accepted 11-07-2016

\section{INTRODUCCIÓN}

Hasta la fecha han sido numerosos y notables los estudios realizados sobre los cabildos catedralicios españoles. Entre otras cuestiones, se ha investigado la sociología de sus miembros, con todo lo que ello abarca, procedencia

* Este trabajo forma parte del proyecto de investigación: «Religiosidad y reforma católica en el noroeste de la península ibérica durante el Antiguo Régimen» (HAR2013-44187-P), financiado por el Ministerio de Economía y Competitividad.

1 maria-jose.perez@unileon.es / ORCID iD: http://orcid.org/00000001-5490-3895 social, geográfica, edad o formas de acceso a canonicatos y dignidades, la dinámica económica de los mismos o el universo de las mentalidades. ${ }^{2}$ En el caso concreto de la provincia de León, Villacorta Rodríguez le dedicó un extenso

\footnotetext{
2 Nuestro trabajo se enmarca en una corriente historiográfica muy amplia, cruzada por diversas líneas de investigación. Las ricas recopilaciones que presentamos a continuación han sido sobrepasadas con un importante volumen de trabajos publicados con posterioridad. López López 2005: 547-584; Marín López 2007: 75-112; Morgado García 2007: 75-100. Por otro lado, a lo largo del trabajo iremos comparando nuestros resultados con los de otros cabildos, para conocer las posibles semejanzas o diferencias que existían entre ellos.
} 
trabajo al de la capital - no olvidemos que existía otro en Astorga-, en el que abarcó una amplio marco cronológico y espectro temático: la corporación capitular, la jerarquización de sus miembros, la disciplina, las finanzas, sus relaciones con otras instituciones o la asistencia social ${ }^{3}$; por su parte, Fernández del Pozo, centró sus trabajos en las rentas y evolución de las mismas. ${ }^{4}$ En este momento nos ceñiremos a cuestiones estrictamente sociales, centradas en un grupo concreto, el de los canónigos. ${ }^{5}$ Para tal fin, vamos a abordar, a lo largo de la Edad Moderna, cuestiones relacionadas con la naturaleza de los mismos, la edad de ingreso o defunción, la promoción o formas de corresidencia, este último aspecto solo para un momento concreto, mediados del siglo XVIII. ${ }^{6}$ Así pues, y dadas las dimensiones metodológicas que nos ofrece el tema, este trabajo constituirá una primera aproximación a aquella realidad social.

El cabildo de leonés había surgido en la Alta Edad Media y a lo largo de la siguiente etapa, entre los siglos XI y XIII, se fue reorganizando como institución espiritual y de gestión económica. ${ }^{7}$ En este sentido, sus bienes patrimoniales, que en un primer momento habían formado una masa común, se desgajaron en beneficios y prebendas y la concesión de las mismas dejó de estar al arbitrio del obispo; así mismo, se fijó el número de canonjías, su dotación o la capacidad de intervención del prelado en estas cuestiones. Pero los cambios en el cabildo legionense aún continuaron en la Edad Moderna, fundamentalmente tras el Concilio de Trento. ${ }^{8} \mathrm{~A}$ lo largo de este periodo histórico cabe destacar las constantes fricciones entre canónigos y obispos, a causa de las visitas pastorales, protocolo, provisiones o las mudanzas relacionadas con el número de capitulares, con lo que ello implicaba a la hora de reorganizar las prebendas. ${ }^{9}$

A mediados del siglo XVIII, el clero suponía el 6,2\% ${ }^{10}$ de las unidades familiares de la ciudad de León y, entre ellas, el porcentaje más elevado correspondía a hogares encabezados por miembros del cabildo catedralicio. Esta institución que poseía un notable poder económico en la ciudad, controlaba un nada despreciable patrimonio inmueble, era propietaria de un elevado porcentaje $(69,5 \%)$

3 Villacorta Rodríguez 1974.

4 La siguiente investigación ofrece una síntesis de aquellas: Fernández Del Pozo 2004: 345-475.

5 Sobre el clero rural leonés, se han realizado ya algunas investigaciones: Pérez Álvarez 2016: 1-17; Rubio Pérez 2013: 129-166. Por otro lado, y aunque son conocidas investigaciones sobre la conflictividad interna en los cabildos, nosotros, en este momento, no disponemos de documentación suficiente para abordar esa cuestión. Callado Estela 2001 y 2011: 337-370.

6 Solamente disponemos del libro de familia del catastro del marqués de la Ensenada para conocer las formas de corresidencia, no obstante, algunas escrituras procedentes de los protocolos eclesiásticos, nos vienen a avalar algunos comportamientos que estaban en vigor en aquel momento.

7 Sánchez González 2000: 21.

8 La evolución del cabildo, desde sus orígenes, puede consultarse en Villacorta Rodríguez 1974; una síntesis del proceso la recoge el mismo autor en 2004: 199-220.

9 Sobre el enfrentamiento entre el cabildo y el obispado por las visitas, consultar García Oro 2004: 545-569; Goñi Gaztambide 1975: 425-458; Villacorta Rodríguez 1974: 484-505. Fricciones que también tuvieron lugar en otras diócesis, como Oviedo o Valladolid. Egido López 2000: 24-25; López López 2010: 131-155.

10 Porcentaje muy similar al burgalés, 6,5\%, Sanz de la Higuera 2006: 549. del terreno agrícola y superficie pratense que estaba en manos del clero; no era desdeñable su participación en la propiedad de la cabaña ganadera, como tampoco en los molinos, y, por supuesto, a todo ello se deben añadir los ingresos derivados de las rentas decimales y de los bienes que poseía fuera de la ciudad. ${ }^{11}$

Respecto al número de personas que componían el cabildo leonés, al margen de beneficiados y demás cargos que lo integraban, podemos considerar, si lo comparamos con los de otras ciudades, que se trataba de una institución nutrida ${ }^{12}$, más aún si tenemos en cuenta el tamaño de la ciudad y que a poca distancia estaba el de Astorga. ${ }^{13}$ Hasta 1634 estaba constituido por 70 canónigos, 12 dignidades y 4 canonicatos de oficio; a partir de esa fecha el primer grupo se redujo a 5514; y en 1761 , cuatro dignidades se incorporaron a oficios y disminuyó, nuevamente, el número de prebendados, que se fijó en $28 .^{15}$ La pérdida de peso cuantitativo de este colectivo fue, en gran medida, consecuencia de la solicitud hecha por el cabildo al monarca y a la Santa Sede de rebajar su número para que, redistribuidos los beneficios, sus titulares pudieran

11 Rubio Pérez 1993. Sobre las posesiones urbanas que poseía en la recta final de la Edad Media el cabildo leonés, la estructura de las edificaciones o su rentabilidad, puede consultarse García, Nicolás y Bautista 1990. La información sobre la procedencia detallada de esas rentas y el capítulo de gastos, nos la ofrece Fernández Del Pozo 2004 : 435-475.

12 Por ejemplo, la ciudad de Córdoba, muchísimo más poblada que León, contó con 5 dignidades y 20 canónigos a lo largo de toda la Edad Moderna. Si bien, en esta comparación hemos de tener en cuenta que al leonés lo avalaba una larga trayectoria histórica. Menor era el número de capitulares también en Granada, Cartagena, Mallorca, Évora, Zamora, los gallegos, excepto Santiago, o Burgos. Aún después del reajuste que tuvo lugar en 1761 , el leonés superaba en número al gaditano, al ovetense o al de Lérida. Casado Casado 1980: 31-33; Castillón Cortada 1990: 102; Díaz Rodríguez y López-Salazar Codes 2014: 42; García Pérez 2014; Irigoyen López 2000: 21; López López 2010: 131-155; Marín López 1998: 23; Morgado García 1990: 389 402; Pérez López 2000: 21 y 25; Rey Castelao 1990: 579-600; Sánchez Herrero 1995: 420; Vázquez Lesmes 2008: 813-830. En Astorga, también fue disminuyendo el número de canónigos conforme avanzaba la Edad Moderna. El siglo XVII comenzó con 41 y acabó con 36 y en el XVIII se pasó de 26 , en 1730 , a 22 , en la década de los ochenta. Al igual que los gallegos, exceptuando el de Santiago y no al mismo nivel, el leonés, fundado en una época en que la ciudad era cabeza de reino, en la Edad Moderna fue perdiendo importancia frente a otros más modernos y ricos pero continuaba cumpliendo su papel social, como el dar una lustrosa a la vez que fructífera salida profesional a los varones de los linajes que podían afrontar el costo que ello suponía. Rey Castelao 1990: 582.

13 Las densidades parroquiales en la diócesis de León y Astorga son importantes si las comparamos con las de otros territorios. Ahora bien, esas pierden fuerza si se calcula la proporción entre eclesiásticos y seglares. Carasa Soto 1993; Hermann 1982: 151-149.

14 Las dificultades económicas fue lo que llevó al cabildo a recurrir a la Santa Sede para reorganizarlo. Quedaría constituido por 55 canonicatos titulares, 12 dignidades y 4 canónigos de oficio. Risco 1787: 184; Villacorta Rodríguez 1974: 55-64. Catorce años antes había tenido lugar un reajuste similar en la diócesis de Oviedo, mantuvo el número de dignidades, 15 , y se redujo el de canónigos, de 50 a 41 . Los motivos, al igual que en León en 1634 y 1761, fueron la escasa dotación de las prebendas. López López 2010: 143-146.

15 Concretamente, las dignidades incorporadas fueron las de maestreescuela, tesorero, prior y abad de San Guillermo que pasaron al doctoral, magistral, penitenciario y lectoral, respectivamente. Villacorta Rodríguez 1974: 62. 
disfrutar de una economía más holgada. ${ }^{16}$ Pero resulta muy complicado conocer la importancia que tenían aquellas asignaciones en el monto global de los ingresos de los canónigos, pues, además de las prebendas, gozaban de otros importantes estipendios difíciles de cuantificar. Nos referimos a las herencias, algunas muy sustanciosas ${ }^{17}$, las rentas que obtenían de los bienes adquiridos por ellos, las inversiones en censos y juros, o las capellanías ${ }^{18}$, muchas de sangre, algunas ubicadas en sus localidades de origen y otras en lugares más alejados.

El papel asumido por los cabildos catedralicios en la época medieval aún mantenía gran parte de su proyección en la Edad Moderna, sobre todo en el plano formativo, aunque habían ido surgiendo otras instituciones religiosas que también ejercían labores docentes. ${ }^{19}$ Ejemplo de aquella actividad fue la fundación, en 1646, del colegio de San José, por el obispo D. Bartolomé Santos Risoba, dependiente del cabildo y focalizado en la formación musical y clerical ${ }^{20}$; o la escuela de gramática, dotada por aquella corporación en el siglo XVIII. Pero, además de ejercer directamente la dirección de esos centros en la capital, el legionense era patrono de otras instituciones de enseñanza, como el colegio de León en Alcalá, fundado a finales del siglo XVI por el obispo Trujillo. ${ }^{21}$

16 Una situación similar a la de 1634 se repitió en el siglo XVIII, sí bien en este caso no se obró con toda limpieza para lograr la reducción, tanto en la presentación de las cuentas como en el momento elegido, aprovechando que la sede episcopal se hallaba vacante. Risco 1787: 184; Villacorta Rodríguez 1974: 55-64.

17 Los ingresos de las dignidades y canónigos leones pueden consultarse en ibídem: 410-425. Los poderes para que los bienes heredados de sus padres fueran administrados por hermanos $u$ otros familiares aparecen con frecuencia en la documentación notarial. Por ejemplo, los hermanos Soto Vitoria, lo expidieron en 1720; el mismo año, D. Juan Francisco Biergol, considerando que tenía bienes más que suficientes para vivir cómodamente, donó la herencia recibida de sus padres en un tío materno, caballero y miembro del Consejo Real, que residía en Madrid; a un hermano, que entre otros título ostentaba el de marqués de Villel y vizconde de Malleza, le cedió sus legítimas paternas y maternas, lo propio hizo D. Tomás Ángel Gutiérrez Gómez, en este caso a una hermana. El abanico de recursos económicos de los que gozaban los capitulares, además de la prebenda, era muy variado. Irigoyen López 2000: 151-157. A.H.D.L. Protocolos Notariales.

18 D. Antonio de Horcasitas Avellaneda, natural del valle de Arcentales, nombrado a comienzos del siglo XVII obispo de Calahorra, disfrutaba de las rentas de una capellanía que había fundado en Toledo D. Francisco Horcasitas; D. Pedro Teresa Riopa, recibía los ingresos de un beneficio que en Berlanga de Duero o D. Manuel Soto y Vitoria era titular de una capellanía que había fundado en su localidad de origen, Viguera, su cuñado. A.H.D.L. Protocolos Notariales.

19 Sobre las funciones del cabildo en la sociedad Latorre Ciria 2009: 547-548. Sobre la vertiente docente de esa institución en la ciudad de León, consultar Prieto Escanciano 2004: 241-250.

20 El seminario leonés de San Froilán no estuvo a pleno rendimiento hasta el siglo XVIII. Los primeros conatos, en el siglo XVI, se deben al prelado D. Francisco Trujillo, quien tuvo que enfrentarse a los numerosos obstáculos que le puso el cabildo. Esas fricciones cabildo-obispado, por la fundación de ese centro de instrucción, se repitió en otras diócesis -Oviedo, Pamplona, Huesca, Vich, Sevilla, Badajoz o Mallorca-, por dos cuestiones, fundamentalmente: la económica y la formativa, hasta entonces competencia de los cabildos. Fernández Conde 1948: 43-53; Fernández Terricabras 2000: 291-360. Sobre la fundación y desarrollo del seminario leonés, ver Martín García 2012: 131-156; para Oviedo, López López 2010: 146.

21 Trujillo 1926. La obra fue escrita a finales del siglo XVI y prologada en el XVIII por D. Carlos Espinós, canónigo en León.
En este trabajo utilizaremos como fuentes principales, para el estudio sociológico de los canónigos leoneses, los expedientes de limpieza de sangre cuyo contenido difiere notablemente de unos a otros. Pues si en algunos casos ofrecen multitud de detalles en otros se limitan a lo estrictamente básico que les otorgue validez. Una segunda fuente manejada fue el libro Récesit, en el que debía de anotarse lo que serían todos los ascensos en la carrera eclesiástica, desde la toma de la prebenda hasta el fallecimiento. Así mismo, nos han sido de gran apoyo los protocolos eclesiásticos y, por supuesto, el libro de familia del catastro del marqués de la Ensenada. La utilidad de este último la hemos concentrado en el último apartado del trabajo.

\section{CANÓNIGOS, DIGNIDADES Y OFICIOS: ORIGEN SOCIAL, NATURA- LEZA Y ENDOGAMIA}

Llegar a ocupar una canonjía sabemos que era un privilegio que estaba reservado a las capas socioeconómicas más pudientes de la sociedad, pues solamente el costo de las pruebas e informaciones que "corresponden hacerse de dicho canonicato en virtud de las bulas apostólicas» era muy elevado. ${ }^{22}$ No obstante, ese no fue impedimento para que algunas familias pudieran colocar a más de un descendiente en los cabildos. En el de León, desde finales del siglo XVI hasta el primer tercio del XIX, hubo, al menos, 31 familias que ingresaron a dos hijos e, incluso, alguna a tres; $y$, por supuesto, los casos de primos carnales o tíos y sobrinos eran muy frecuentes, pero, debido al juego de apellidos y dobles residencias, no nos atrevemos a ofrecer cifras.

Durante la Edad Moderna hubo familias en las que no se saltó ninguna generación en la que al menos uno de sus miembros detentara alguna canonjía en el cabildo leonés. Entre los autóctonos, por ejemplo, D. Luis Robles Lorenzana Santisteban entró en 1606, once años después lo hizo un primo carnal suyo, D. Francisco Badajoz Lorenzana; a la generación siguiente pertenecían D. Francisco y D. Luis Aguirre Lorenzana, que ingresaron en 1627 y 1642, respectivamente. Abundando en esta familia, señalar que $D$. José Javier Gutiérrez Porras, en 1726, año en que se elaboró su expediente de limpieza de sangre, apuntaba que entre otros miembros de la familia que habían sido o aún eran

22 D. Pedro Robles Villafañe, quien hizo las pruebas de limpieza para entrar de canónigo en 1728 , se vio en la necesidad de tomar un préstamo de 12.540 reales para «el desempeño de las bulas de su canonicato». Se obligó, junto a su padre y los garantistas, a devolver el dinero en seis meses. Ante la imposibilidad de afrontar el pago en la fecha prevista, optó por otro sistema. El prestamista, D. Juan Carralón, vecino de Madrid, recibiría la mitad de todo lo que le correspondiera, en cada tercia, o cuatrimestre, hasta saldar la deuda. A.H.D.L. Protocolos Notariales. El elevado coste que suponía acceder a estos puestos era un «filtro» que excluía a las capas más humildes de la sociedad. Vázquez Lesmes 1999: 599. El uso de don en los ascendientes de los que pretendían una canonjía y el nivel social de las personas a las presentan como parientes para reforzar sus limpiezas de sangre, nos revela la alcurnia de los linajes a los que estaban reservados los cabildos. Cuestión ésta más que conocida en otras ciudades, en las que quedó avalada por los elevados porcentajes de aspirantes perecientes a la nobleza titulada o a otros grupos de elevada extracción social, como, por ejemplo, Santiago, Orense, Cádiz, Jaén o Cataluña. Coronas Vida 1986: 102-103; Fatjó Gómez 1993:149159; Morgado García 1990: 393; Rey Castelao 1996: 163; Rodicio Pereira 2013: 140. 
prebendados en la catedral leonesa, además de algunos de los ya señalados, se encontraban D. Anastasio Lorenzana, D. Francisco y D. Santiago Gutiérrez y D. Juan de Porras. ${ }^{23}$ Pero el tejido familiar no se ceñía a esa institución, sus redes también se extendían a los cabildos de San Marcos y San Isidoro y por diferentes parroquias. De fuera de la ciudad podremos el ejemplo de los García Aplicanos, de la rama que permaneció en Pedroso, La Rioja, y de la que se estableció en Rioseco. En 1691 entró D. Baltasar García Aplicanos, en 1701 lo hizo su sobrino, D. Francisco, y dos décadas después D. Diego Viguera Escudero, sobrino nieto del anterior, y D. Pedro Alenson Viguera, hijo de una hermana del último. Esta familia también extendió sus tentáculos al arzobispado de Santiago, donde llegaron dos primos carnales de D. Diego, D. José y D. Pedro, canónigo y abad, respectivamente. Pero los destinos religiosos de aquel linaje no se reducían al norte y noroeste peninsular, puesto que, además de los señalados y de diferentes sacerdotes que prestaban servicio en La Rioja o Galicia, al menos tres miembros más ocuparon puestos relevantes en tribunales de la Inquisición, dos en Madrid y otro en Lima. Un caso similar lo encontramos en la familia de origen riojano, emparentada con leoneses, Soto y Vitoria. Pero esa endogamia e influencias ${ }^{24}$ que había entre capitulares iba más allá de lo que nos puedan reflejar los expedientes de limpieza de sangre y que hemos ido completando con poderes o testamentos, algunos hacen alusión a otros parientes que habían formado parte, o aún estaban vivos, en puestos relevantes o de segundo nivel dentro del cabildo. A todo ese mundo de consanguineidad, en diferente grado que había dentro de la institución, hay que añadir la vinculación parental que tenían con párrocos y capellanes que ejercían en la diócesis leonesa o fuera de ella. ${ }^{25}$

Pero las redes sociales que se iban tejiendo en el mundo eclesiástico, dentro y fuera del cabildo, también acababan por prolongarse al laico. ${ }^{26}$ Por ejemplo, el marqués de San Isidro, D. Joaquín Ruiz Gómez, pasó a casarse a Asturias, a mediados del siglo XVIII, con Dña. Teresa de Prado, hermana de un canónigo; durante el mandato del D. Cayetano Cuadrillero Mota, obispo de León, en el último cuarto del siglo XVIII, entró un sobrino a formar parte del cabildo y pocos años después un regidor perpetuo leonés, $D$. Manuel Alejo García de Brizuela, se trasladó a Palazuelo de Bendija, de donde procedía esa familia, a contraer nupcias con una

${ }^{23}$ Si bien los parentescos entre capitulares y la prolongación de linaje es un modelo reiterado en otros cabildos, el caso de esta familia, que no es excepcional, podemos comprobar cómo su presencia en la institución se prolongó más de dos generaciones. Cabeza Rodríguez 1996: 251; Fatjó Gómez 1993: 54.

24 Situación que se repite en otros cabildos, como el cordobés o el de Jaén. Coronas Vida 1986: 105-108; Vázquez Lesmes 1999: 601-602.

${ }_{25}$ En algunas familias es fácil constatar la obstrucción a una diseminación del linaje que merme la capacidad económica del mismo. A este respecto, y para los siglos de la Alta Edad Moderna, Delille estudió como diferentes familias italianas fueron cambiando o adaptando las estrategias (2015: 149-164).

26 Como ha señalado López López, «las canonjías no eran sólo una aspiración de promoción clerical sino también un medio para el ascenso social e incluso político al servicio de personas y linajes» (2010: 150). Un importante peso tuvieron los canónigos palentinos en el control y estrategias familiares. Cabeza Rodríguez 2000: 41-46; con abundantes ejemplos nos ilustran para la diócesis de Cartagena, Irigoyen López 2000: 59-64. sobrina del prelado, hermana del canónigo.

Indudablemente, y como ocurría en otros cabildos, las bolsas de reclutamiento de los canónigos se situaban en los estamentos con mayor capacidad económica y poder social, vinculados a los caballeros regidores, a la pequeña y mediana nobleza, los militares de alta graduación y profesionales. ${ }^{27}$ En el leonés encontramos que muchos de los prebendados tenían hermanos que eran regidores en sus localidades de origen, o en otras ciudades, y también es frecuente hallar algunos directamente emparentados con títulos nobiliarios. Por ejemplo, D. José Bustamante pertenecía a la familia de los marqueses de Villatorre, D. Pedro Manuel Isla y Delgado, era hijo de los condes de Isla; también tenían representación los marquesados asturianos de Villel o Ferrera. Entre los de origen local, no faltaron miembros del marquesado de Inicio y San Isidro, del vizcondado de Quintanilla Flórez o de los condes de Catres. Por supuesto, estuvieron presentes hijos de pequeños señores jurisdiccionales y de militares. No encontramos, por el contario, una reseñable presencia aristocrática, ya que esas familias reservarían a sus hijos para cabildos de mayor prestigio. ${ }^{28}$

En el archivo catedralicio de León se conservan, restando los repetidos, 938 expedientes de limpieza de sangre realizados entre 1544 y $1850^{29}$, si bien hasta 1562 no hay continuidad en la serie. ${ }^{30} \mathrm{~A}$ su vez, dentro de esa cifra, los hay dobles, es decir, se hizo uno solo para dos hermanos que pretendía una canonjía el mismo año, lo que les ahorraba una cantidad de dinero importante, caso de D. Saturnino y D. Carlos Fernández Pantoja, en 1760. Si bien esta circunstancia no fue muy frecuente, puesto que el proceso solía repetirse, como, por ejemplo, los hermanos Trespalacios Mier, D. Pedro y D. Antonio, quienes lo realizaron de forma individual en 1671 y 1676, respectivamente. Casi dos tercios de aquellos expedientes pertenecen a canónigos o coadjutores, es decir, a los sustitutos en vida del titular de la prebenda. Un segundo grupo, pero ya a considerable distancia, lo conforman los bachilleres y cofrades; seguidos por los que accedían a una dignidad, directamente o como futuro relevo; prácticamente el mismo peso tuvieron los que hemos agrupado bajo el epígrafe varios, donde hemos englobado cargos menores (pertiguero, racionero, capellán de San Carlos o maestro de capilla); menor fue el de los pretendientes a los oficios $y$, finalmente, hay un pequeño grupo de los que desconocemos cuál era su objetivo (cuadro no 1).

\footnotetext{
27 Fatjó Gómez 1993: 155-159; Vázquez Lesmes 2008: 820-823.

28 Caso de la sede toledana. Sánchez González 2000: 31.

29 Desconocemos los motivos por los que se repitieron, pues de las pruebas no había resultado mácula. Por otro lado, hay algún que otro expediente, como el de D. Ignacio Pascual Barra, que, aunque aparece como tal, no está completo, pues no fue necesario repetir todas las pruebas, ya que su «limpieza» había sido demostrada cuando entro como canónigo en Tuy. Por otro lado, la regulación de cómo debían de hacerse tales expedientes a los aspirantes, fue elaborada y ampliada, en la Edad Moderna, por los prelados D. Pedro Manuel, en 1525, D. Andrés de la Cuesta, en 1562, y D. José Gregorio de Rojas y Velázquez, en 1669. Villacorta Rodríguez 2004: 81-84.

30 Anteriores a aquella fecha solamente se conservan uno de 1554
} y otro de 1553 . 
CUADRO № 1

Objeto de las limpiezas de sangre en el cabildo de la catedral de León entre 1544 hasta 1850

\begin{tabular}{|c|c|c|c|c|c|c|c|c|c|c|}
\hline & \multicolumn{2}{|c|}{$\mathrm{XVI}$} & \multicolumn{2}{|c|}{ XVII } & \multicolumn{2}{|c|}{ XVIII } & \multicolumn{2}{|c|}{ XIX } & \multicolumn{2}{|c|}{ TOTAL } \\
\hline & № & $\%$ & № & $\%$ & № & $\%$ & № & $\%$ & № & $\%$ \\
\hline Canónigos & 110 & 68,3 & 292 & 67,0 & 146 & 56,2 & 47 & 58,0 & 595 & 63,4 \\
\hline Bachilleres y cofrades & 26 & 16,1 & 73 & 16,7 & 48 & 18,5 & 17 & 21,0 & 164 & 17,5 \\
\hline Varios & 10 & 6,2 & 23 & 5,3 & 28 & 10,8 & 4 & 4,9 & 65 & 6,9 \\
\hline Dignidades & 12 & 7,5 & 30 & 6,9 & 14 & 5,4 & 7 & 8,6 & 63 & 6,7 \\
\hline Oficios & 1 & 0,6 & 14 & 3,2 & 20 & 7,7 & 6 & 7,4 & 41 & 4,4 \\
\hline Desconocidos & 2 & 1,2 & 4 & 0,9 & 4 & 1,5 & & & 10 & 1,1 \\
\hline TOTAL & 161 & 100 & 436 & 100 & 260 & 100 & 81 & 100 & 938 & 100 \\
\hline Media anual & $2,9-4,2(*)^{32}$ & & 4,4 & & 2,6 & & 0,8 & & 2,7 & \\
\hline
\end{tabular}

La media anual de aspirantes por siglos fue experimentando un retroceso considerable, pasando de 4,2 en el siglo XVI a 0,8 en el XIX, con valores medios de 4,4 en el siglo XVII - que tal y como se desprende de la tabla sería la más elevada- y 2,6 en el XVIII. Si nos centramos en los canónigos, que era el grupo más numerosos en la estructura capitular, esas cifras fueron: $2,3,2,9,1,5$ y 0,5 en los siglos XVI, XVII, XVIII y XIX, respectivamente. A la luz de estos datos, podría parecer que la trayectoria no concuerda con las disposiciones aprobadas, a petición del cabildo, por la Santa Sede en 1634, de rebajar el número de canonjías de 70 a 55, lo que suponía algo más del $21 \%$. Pero si en esa centuria realizamos cálculos parciales comprobamos como, efectivamente, se cumplió con las disposiciones de la bula, pues antes de aquella fecha la media de limpiezas para ocupar canonjías era de 3,7 y con posterioridad pasó a 2,6 , lo que supone una reducción del $29,8 \%$. A su vez, y reflejo del descenso experimentado en el siglo XVIII, tras el reajuste de 1761, se produce la caída del número de canónigos y dignidades que entablaron, aun teniendo en cuenta que no siempre todos se encontraban en la ciudad en el mes de septiembre que era cuando comenzaba el curso. Si en la primera mitad de siglo lo hicieron entre 50 y 59, la segunda ya comenzó con una docena menos y a partir de los sesenta oscilaron entre los 36 y 40 .

Ahora bien, en cualquier caso, hemos de tener en cuenta que no todos los canónigos que pasaron por el cabildo leonés hicieron las pruebas de limpieza en esta ciudad, o al menos no se conservan. De hecho, si comparamos los datos del libro Recésit ${ }^{32}$, o de tabla, elabo-

31 Los dos cálculos corresponden al hecho de que, como hemos señalado, hasta 1562 la serie no empieza a ser continua. El primero, 2,9, sería tomando como punto de partida 1544 y el otro, 4,2, si lo hacemos con 1562.

32 A.C.L.L. 10.744. A su vez, la misma fuente catedralicia nos ha servido para conocer, entre otras cuestiones, la anulación, en 1812, de la canonjía de 4 personas, - «a causa de ser provisto por rado entre 1680 y los inicios de la década de los treinta del siglo XIX, con el listado de expedientes de esas fechas, evidenciamos como en aquel aparecen anotados 46 que no se recogen en la colección de expedientes de limpieza. Por otro lado, también hemos cotejado los que aparecen en dicho libro con los que deberían aparecer en el de familia del catastro del marqués de la Ensenada. El resultado fue que 12 no estaban asentados en el de tabla y 3 a la inversa, y tenemos constancia de que estaban vivos cuando se realizó la encuesta catastral. Otra muestra de las dificultades para conocer fehacientemente el universo capitular es que hemos encontrado algún caso, en la toma de posesión de una canonjía, que se recoge en las actas capitulares que su titular no aparece entablando ni se conserva su expediente de limpieza. ${ }^{33}$ Por lo tanto, el ceñirnos exclusivamente a esta última fuente para conocer la evolución cuantitativa de los aspirantes a canonjías, dignidades y oficios no exime de un margen de error, aunque no parece muy elevado, como tampoco lo está el Recésit. En favor de este último tenemos que señalar su utilidad para acercarnos a la evolución profesional de los canónigos o conocer su fecha de defunción, pero los responsables de su elaboración no fueron tan minuciosos como cabría desear.

el gobierno intruso»- - Se trataba de Mariano Fernández Chicarro, Juan Chaca González, Andrés Martínez Pérez y Vicente Paniagua Daniel.

33 Caso de D. Ramón Campuzano, quién, según las actas capitulares tomó posesión del canonicato en 1753 y realizó su limpieza en León. De hecho, dos de los canónigos - Sr. Rodríguez y Sr. Rubio- que se desplazaron para recabar las informaciones pertinentes se pusieron enfermos y mandaron una nota al cabildo para comunicarles el retraso de su viaje. A.C.L. Libros de Actas, 10039-400. 
CUADRO no 2

Evolución de las entradas de canónigos, dignidades y oficios en el cabildo catedralicio de León ente 1550 y 1850

\begin{tabular}{|c|c|c|c|c|c|c|c|c|c|}
\hline & \multicolumn{3}{|c|}{$1550-1634$} & \multicolumn{3}{|c|}{ 1634-1761 } & \multicolumn{3}{|c|}{$1761-1850$} \\
\hline & \multicolumn{2}{|c|}{$\begin{array}{c}\text { Miembros del } \\
\text { cabildo }\end{array}$} & \multirow{2}{*}{$\begin{array}{c}\% \text { de } \\
\text { expedientes } \\
\text { de limpieza de } \\
\text { sangre. }\end{array}$} & \multicolumn{2}{|c|}{$\begin{array}{l}\text { Miembros del } \\
\text { cabildo }\end{array}$} & \multirow{2}{*}{$\begin{array}{c}\% \text { de } \\
\text { expedientes } \\
\text { de limpieza de } \\
\text { sangre }\end{array}$} & \multicolumn{2}{|c|}{$\begin{array}{l}\text { Miembros del } \\
\text { cabildo }\end{array}$} & \multirow{2}{*}{$\begin{array}{c}\% \text { de } \\
\text { expedientes } \\
\text { de limpieza de } \\
\text { sangre }\end{array}$} \\
\hline & № & $\%$ & & № & $\%$ & & № & $\%$ & \\
\hline Canónigos & 70 & 81,4 & 87,5 & 55 & 77,5 & 82,0 & 28 & 70,0 & 79,3 \\
\hline Dignidades & 12 & 14,0 & 8,4 & 12 & 16,9 & 9,7 & 8 & 20,0 & 7,2 \\
\hline \multirow[t]{2}{*}{ Oficios } & 4 & 4,7 & 4,2 & 4 & 5,6 & 8,3 & 4 & 10,0 & 13,5 \\
\hline & 86 & 100 & 100 & 71 & 100 & 100 & 40 & 100 & 100 \\
\hline
\end{tabular}

Volviendo a los expedientes, en ellos se debería reflejar la proporcionalidad que existió entre canónigos, dignidades y oficios. El reparto estaría mediatizado por una serie de variables, tales como la mortalidad o la movilidad geográfica. Y, por supuesto, el que nosotros podemos manejar se aleja del estipulado en la medida en que carecemos de documentación, circunstancia que hemos constatado pero no podemos cuantificar. No obstante, y a pesar de todo ello, se puede comprobar como existió cierta concordancia entre el volumen de aspirantes y necesidades del cabildo. ${ }^{34}$ El porcentaje de oficios que se puede extraer de las de limpieza de sangre es el que más concuerda con la distribución de puestos, aunque la cifra de los que cumplieron con aquel requisito fue más elevada de lo que marcaban las necesidades. Esta circunstancia estaría provocada por decesos prematuros, traslados o ascensos, y de hecho, de los tres grupos, fue el colectivo que proporcionalmente mayor movilidad tuvo. La promoción derivaría de la formación intelectual que se les exigía para ocupar el puesto y que después les serviría de acicate para impulsar su carrera eclesiástica. Por el contrario, el volumen de dignidades fue el que más se apartó del patrón, como resultado, en parte, del ascenso interno. ${ }^{35}$ Entraban como canónigos y eran elevados a una dignidad cuando quedara vacante y no existía candidato directo (cuadro no 2).

Centrándonos en las procedencias del grupo mayoritario, los canónigos, cuya localidad de origen no ofrece dudas para su ubicación, podemos comprobar cómo estuvieron representadas, en proporciones muy variadas, todas las comunidades peninsulares (cuadro no 3)..$^{36}$ Lógicamente, el mayor porcentaje correspondía a la de Castilla y León, algo más de la mitad (57\%), si bien dentro de ésta resulta evidente que la provincia con mayor peso fue la de León $(25,5 \%) .{ }^{37}$ Entre esos leoneses, un $40 \%$ eran de la capital y

34 Para realizar los cálculos hemos eliminado los coadjutores, que no serían titulares hasta que no falleciera el canónigo al que aspiraba a darle el relevo.

35 Sobre la falta de proporcionalidad en los expedientes de limpieza leoneses en el siglo XVI, véase Iglesias Ortega 2012a: 18.

36 Hemos agrupado las procedencias en función de las actuales provincias y comunidades autónomas para facilitar la lectura de los resultados.

37 En esta cifra están englobados los oriundos de toda la provincia, por lo que queda muy alejada de la gaditana, dónde el $40 \%$ eran nativos de la ciudad. Diferencia que resulta lógica si comparamos el tamaño y estructura socioeconómica de ambas ciudades. Morgado García 1990: 392. el resto procedían del ámbito rural, representación que no concuerda con el sistema de poblamiento -eminentemente rural- pero sí con el establecimiento de los grupos de poder. A los autóctonos les seguían los vallisoletanos, palentinos, burgaleses, sorianos, zamoranos, segovianos y abulenses, por ese orden, algunos con ascendencia leonesa. Ahora bien, esos porcentajes experimentan un ligero cambio si tomamos como referencia la diócesis (cuadro no 4). Hemos de tener en cuenta, por un lado, que la legionense se adentraba en Zamora, Palencia, Valladolid y Cantabria y, por su parte, en la provincia de León había demarcaciones que pertenecían a los distritos de Astorga y Oviedo. Pues bien, a tenor de los resultados que nos ofrecen los nuevos cálculos, los canónigos procedentes de la diócesis de León representaron, en conjunto, un $32,2 \%$, cifra que fue creciendo desde 1552 hasta 1800. En el mismo periodo, y entre los leoneses, los adscritos a Oviedo y Astorga, tuvieron un peso que osciló entre el 17,4\%, del siglo XVI, y el 41,7\%. El gran cambio tuvo lugar en el XIX, los diocesanos leoneses retrocedieron al $21,3 \%$ y fueron los maragatos y ovetenses los que apuntalaron la representación de esta provincia. En ese resultado hemos de tener en cuenta las circunstancias del periodo, que inició con un conflicto bélico y una sede episcopal vacante, que algunos leoneses aprovecharon para acceder a canonicatos que no tardaron en anularles. En cualquier caso, ya analicemos las procedencias por circunscripciones civiles o eclesiásticas, la composición geográfica del cabildo leonés queda muy alejada del murciano, los andaluces o catalanes. ${ }^{38}$ Consecuencia, en

38 En el cordobés, desde finales del XVII a mediados del XVIII, eran andaluces el $75 \%$, ligeramente más bajo era ese porcentaje en Jaén en el primer tercio del XVIII, 74,3 y el de los jienenses 54,5. En Cádiz, en la centuria dieciochesca, eran de la diócesis el $67 \%$ de los capitulares; elevada era también la cifra en Aragón en el último tercio del XVIII, Lérida, en la primer mitad del mismo siglo, Tarragona y Barcelona en el siglo XVII o Murcia que, a pesar del considerable descenso que experimentaron en el siglo XVIII, superaba ampliamente a la que encontramos en León. Chaubel I Cabrera 1999: vol. II, 66; Coronas Vida 1986: 108-109; Fatjó Gómez 1993: 150; Fernández Díaz 1990: vol. I, 23-118; Irigoyen López 2000: 228; Latorre Ciria 2009: 552; Morgado García 1989a: 97; Vázquez Lesmes 1983: 89-90. Por su parte, si compramos los datos con territorios más próximos como Galicia, en Santiago, los diocesanos se movieron entre el $20 \%$, de la segunda mitad del siglo XVI y el $31 \%$ de la primera mitad de la centuria siguiente, pero, en cambio, en el siglo XVIII, los gallegos supusieron el $40 \%$, cifra que duplica a la leonesa, si bien hemos de tener en cuenta las dimensiones de uno y otro territorio a la hora de valorar los resultados. No obstante, aun tomando como referencia el reino de León, los procedentes de este ámbito geográfico quedaron muy 
CUADRO № 3

Procedencia de los canónigos que hicieron limpieza de sangre para acceder al cabildo de la catedral de León

\begin{tabular}{|c|c|c|c|c|c|c|c|c|c|c|}
\hline & \multicolumn{2}{|c|}{ 1552-1599 } & \multicolumn{2}{|c|}{ XVII } & \multicolumn{2}{|c|}{ XVIII } & \multicolumn{2}{|c|}{$1800-1850$} & \multicolumn{2}{|c|}{ TOTAL } \\
\hline & № & $\%$ & № & $\%$ & № & $\%$ & № & $\%$ & № & $\%$ \\
\hline León & 23 & 20,9 & 69 & 25,7 & 37 & 29,1 & 12 & 25,5 & 141 & 25,5 \\
\hline Resto de Castilla y León & 42 & 38,2 & 84 & 31,3 & 41 & 32,3 & 7 & 14,9 & 174 & 31,5 \\
\hline Castilla la Mancha & 10 & 9,1 & 23 & 8,6 & 10 & 7,9 & 4 & 8,5 & 47 & 8,5 \\
\hline Asturias & & & 36 & 13,4 & 5 & 3,9 & 4 & 8,5 & 45 & 8,2 \\
\hline La Rioja & 9 & 8,2 & 9 & 3,4 & 6 & 4,7 & 1 & 2,1 & 25 & 4,5 \\
\hline Cantabria & 5 & 4,5 & 11 & 4,1 & & & 2 & 4,3 & 18 & 3,3 \\
\hline Galicia & 2 & 1,8 & 12 & 4,5 & 4 & 3,1 & 2 & 4,3 & 20 & 3,6 \\
\hline País Vasco & 9 & 8,2 & 5 & 1,9 & 2 & 1,6 & 1 & 2,1 & 17 & 3,1 \\
\hline Madrid & 7 & 6,4 & 5 & 1,9 & 3 & 2,4 & & & 15 & 2,7 \\
\hline Andalucía & 2 & 1,8 & 4 & 1,5 & 4 & 3,1 & 4 & 8,5 & 14 & 2,5 \\
\hline Navarra & 1 & 0,9 & 5 & 1,9 & 4 & 3,1 & 2 & 4,3 & 12 & 2,2 \\
\hline Extremadura & & & 1 & 0,4 & 1 & 0,8 & 6 & 12,8 & 8 & 1,4 \\
\hline Aragón & & & & & 5 & 3,9 & 1 & 2,1 & 6 & 1,1 \\
\hline Cataluña & & & & & 4 & 3,1 & 1 & 2,1 & 5 & 0,9 \\
\hline Extranjeros & & & 1 & 0,4 & & & & & 1 & 0,2 \\
\hline Murcia & & & 2 & 0,7 & & & & & 2 & 0,4 \\
\hline \multirow[t]{2}{*}{ Valencia } & & & 1 & 0,4 & 1 & 0,8 & & & 2 & 0,4 \\
\hline & 110 & 100 & 268 & 100 & 127 & 100 & 47 & 100 & 552 & 100 \\
\hline
\end{tabular}

Cuadro no 4

Distribución de los canónigos por diócesis

\begin{tabular}{|c|c|c|c|c|c|}
\hline & 1552-1599 & XVII & XVIII & $1800-1850$ & TOTAL \\
\hline & № & № & № & № & № \\
\hline Diócesis de León & 28 & 90 & 49 & 10 & 178 \\
\hline Provincia de León & 19 & 56 & 30 & 7 & 113 \\
\hline Otras provincias & 9 & 34 & 19 & 3 & 65 \\
\hline \% de la diócesis de León sobre el total & 25,5 & 33,6 & 38,6 & 21,3 & 32,2 \\
\hline Diócesis de Astorga & 4 & 3 & 3 & 3 & 13 \\
\hline Diócesis de Oviedo & & 10 & 4 & 2 & 16 \\
\hline Total & 4 & 13 & 7 & 5 & 29 \\
\hline $\begin{array}{l}\text { \% de los canónigos de las diócesis de Oviedo y } \\
\text { Astorga en territorio de la provincia de León }\end{array}$ & 17,4 & 18,8 & 18,9 & 41,7 & 20,6 \\
\hline
\end{tabular}


parte, del propio tamaño de la ciudad y del restringido número de familias, de un entorno rural tan amplio, que económicamente podían afrontar una inversión tan elevada para ofrecer a sus hijos esa salida profesional.

El segundo grupo con más representación, después de los castellanos y leoneses, era el de los castellanomanchegos $(8,5 \%)$, prácticamente con el mismo porcentaje que los asturianos (8,2\%). Ahora bien, si tenemos en cuenta la extensión de una y otra comunidad autónoma, es mucho más significativa la presencia de los del Principado, que emanaría de la vecindad geográfica y de los lazos de parentesco que existían entre las principales familias leonesas y asturianas. Criterios de proximidad serían también los que influyeron en los cántabros, gallegos o riojanos. Los aspirantes del resto de comunidades tuvieron una representación porcentual inferior al 3,1\%. ${ }^{39}$ Ahora bien, son muy significativos, puesto que reflejan la endogamia geográfica y familiar que generaba el nombramiento de un nuevo obispo. De los 23 que ocuparon la diócesis legionense desde principios del siglo XVI hasta comienzos del XIX, solo uno era natural de la misma, D. Cayetano Cuadrillero, y otro tenía una estrecha relación, D. Juan Álvarez Osorio ${ }^{40}$, hermano del marqués de Astorga. Favoritismos que parece que no estuvieron empañados por las tensas relaciones que existieron entre el cabildo leonés y los diferentes prelados.

Aquella extraterritorialidad de los prelados se proyectó, como hemos señalado, en la creación de fuertes redes familiares y/o geográficas dentro del cabildo. Algunos de esos ejemplos son los de los zaragozanos Ulzurrum Asanza, los toledanos Fernández Pantoja o los Aparicio. A la primera pertenecían dos hijos de los marqueses de Tosos, hermano de D. José, obispo de León entre 1714 y 1718 , año en que falleció, D. Francisco, que ingresó como canónigo en 1717, y D. Pedro, que lo hizo al año siguiente. Por su parte, los hermanos D. José Saturnino y D. Carlos Fernández Pantoja, hicieron sus limpiezas en 1760 , un año antes de que falleciera su tío, el obispo D. Alfonso Fernández Pantoja (1753-+1761), quien, a su vez, tenía un hermano ocupando una canonjía en Astorga. ${ }^{41}$ Un siglo antes, entre 1681 y 1696, había sido obispo de León D. Juan Aparicio Navarro, a cuya sombra llegaron a colocarse en el cabildo leonés, al menos, siete sobrinos. ${ }^{42}$ Procedentes de Brías (Soria), de donde él era natural, llegaron tres hijos de D. Bernabé, hermano del prelado: D. Bernabé y D. José Martínez Núñez, en 1682, quién pos-

lejos de los porcentajes santiagueses, del $54 \%$ y el $63 \%$, antes y después del concordato de 1753. Concretamente, en el siglo XVIII, los canónigos de León, Zamora y Salamanca suponían un 33\% en el siglo XVIII, si bien su representación aumentó respecto a la primera mitad de la centuria, pasando de $28,2 \%$ a $37,9 \%$. Tampoco nuestros datos son comparables a los asturianos, dónde el $86 \%$ de los capitulares que componían el cabildo en la primera mitad del XVIII eran del Principado. Iglesias Ortega 2012a: 17-18 y 20; López López 2005: 150; Rey Castelao 1990: 586.

39 El extranjero que aparece era un portugués con ascendencia extremeña.

40 En el caso de León, entre 1624 y 1800, solamente procedían del clero regular 4 obispos (17,4\%). Porcentaje que queda muy alejado del gaditano, donde alcanza el 40\%. Morgado García 1989b: 31.

41 Este fue el heredero del prelado y a quien le comunicó la forma en que había de hacerse su testamento y reparto de bienes. Para ello expidió el correspondiente poder 1757. A.H.D.L.L. 129.

42 Dos más que el $D$. Pérez Minayo, quien casi un siglo después ocupó la diócesis pacense. Sarmiento Pérez 2005: 99. teriormente ocuparía la mitra asturicense (1707 y 1723), y D. Joaquín, en 1691; otros tres vinieron de la diócesis de Sigüenza, y eran hijos de una hermana del obispo, D. Manuel, D. José y D. Pedro Martínez de Aparicio, en 1682, 1683 y 1693, respectivamente. A la misma familia pertenecían D. Miguel Martínez Rodrigo y D. Pedro Manuel, que hicieron lo propio en 1688 y 1724 . El primero, hermano por parte de madre de los seguntinos y el otro sobrino de los mismos. Este clientelismo desembocó a finales del siglo XVII en la formación de una verdadera camarilla familiar en el cabildo leonés, la de los Aparicio. ${ }^{43}$ Menor parece que fue la influencia, o la contención en este sentido, del obispo navarro D. Martín Celayeta, quien solamente colocó a un hermano, con la dignidad de maestrescuela. Otro ejemplo de aquel proceder es la presencia de los catalanes en el cabildo leonés en el siglo XVIII. Entre 1735 y 1752 ocupó la diócesis de León el barcelonés Fray José Lupia y Roger ${ }^{44}$, hijo de los marqueses de Lupia, al año siguiente entró a gozar de un canonicato D. Fernando Diern; en 1738 lo hizo D. Miguel Rius, que fue mayordomo del prelado y trajo diez años después a un sobrino, D. Francisco Rius; y en 1741, había logrado la prebenda D. Carlos Espinó. ${ }^{45}$ Pero también este prelado «hizo gracia, merced, titulo, colación, provisión y canónica institución del canonicato que vacó por fin y muerte de D. Jacinto de Caño», en el sevillano D. Fernando Manuel Feijó González. Según los datos que hemos podido reunir de este grupo, D. Fernando se trasladó a Gerona en 1746, para ocupar un deanato; D. Miguel marchó a Barcelona en 1738, pero volvería, pues en esta ciudad hizo su testamento en 1744 y un codicilo en 1751; D. Carlos, que fue archivero, también testó en León en 1748 y volvería a hacerlo en 1751, al año siguiente estaba en Barcelona, de donde no tardó en regresar; parece que solo D. Francisco, que falleció en León, en 1800, a la edad de 52 años, tuvo una vida más sedentaria.

Por lo que respecta a los que hicieron las pruebas de limpieza de sangre para ingresar en el cabildo a ocupar alguna dignidad u oficio, y conocemos su naturaleza, comprobamos que prácticamente se repite el esquema de los canónigos (cuadros no 5 y nㅇ 6). El primer puesto era ocupado por los castellanos y leoneses, dentro de los cuales el mayor peso recaía en los últimos. De nuevo, les siguen los oriundos de las provincias limítrofes, ya fuera del Principado o de la propia comunidad autónoma, y después aparecen otras de forma casi testimonial.

43 Las redes familiares, geográficas o de deudos que se iban tejiendo en los cabildos al amparo de un obispo u otros parientes era una práctica muy generalizada. Díaz Rodríguez 2009b: vol. II, 161-174; Fernández Collado 2000: 77-100; Jiménez Sureda 1999: 261-349; Morgado García 2006: 82 y 2008: 16-170; Sánchez González 2000.

44 Sobre sus orígenes, Risco 1787: 181-182.

45 Tanto D. Miguel como D. Carlos, en sus primeros testamentos, dieron muestra de gratitud al obispo. El primero lo nombró heredero, en caso de que le sobreviviera - «por los singulares favores y beneficios que he recibido de Su llustrísima, de que estoy sumamente agradecido»-; D. Carlos, le honró con una manda en la que le autorizaba a escoger todos los libros que estimara oportunos de su biblioteca, por cuanto «se dignó presentarme al canonicato que tengo en dicha iglesia y las demás rentas eclesiásticas que gozo en este obispado ». A.H.D.L.L. 129. 
CUADRO No 5

Procedencia geográfica de las dignidades que ocuparon el cabildo de la catedral de León entre 1552 y 1850

\begin{tabular}{|c|c|c|c|c|c|c|}
\hline & 1552-1599 & XVII & XVIII & $1800-1850$ & TOTAL & \\
\hline & № & № & № & № & № & $\%$ \\
\hline León & 2 & 7 & 4 & 1 & 14 & 22,2 \\
\hline Territorios de la diócesis & 1 & 4 & & & 5 & 7,9 \\
\hline Resto de Castilla y León & 6 & 5 & 2 & 3 & 16 & 25,4 \\
\hline Asturias & & 3 & 5 & & 8 & 12,7 \\
\hline Andalucía & 1 & 1 & 1 & 1 & 4 & 6,3 \\
\hline Castilla-La Mancha & 1 & 2 & & & 3 & 4,8 \\
\hline Galicia & & 3 & & & 3 & 4,8 \\
\hline La Rioja & & 1 & 1 & 1 & 3 & 4,8 \\
\hline País Vasco & 1 & 2 & & & 3 & 4,8 \\
\hline Aragón & & & 1 & 1 & 2 & 3,2 \\
\hline Cantabria & & 1 & & & 1 & 1,6 \\
\hline Madrid & & 1 & & & 1 & 1,6 \\
\hline TOTAL & 12 & 30 & 14 & 7 & 63 & 100 \\
\hline
\end{tabular}

CUADRO № 6

Procedencia geográfica de los que ocuparon oficios el cabildo de la catedral de León entre 1552 y 1850

\begin{tabular}{|c|c|c|c|c|c|c|}
\hline & $1552-1599$ & XVII & XVIII & $1800-1850$ & TOTAL & \\
\hline & № & № & № & № & № & $\%$ \\
\hline León & 1 & 2 & 1 & 2 & 6 & 14,6 \\
\hline Territorios de la diócesis & & 1 & 1 & & 2 & 4,9 \\
\hline Resto de Castilla y León & & 5 & 10 & 2 & 17 & 41,5 \\
\hline Castilla-La Mancha & & 1 & 4 & & 5 & 12,2 \\
\hline Asturias & & 2 & & 2 & 4 & 9,8 \\
\hline Galicia & & 2 & & & 2 & 4,9 \\
\hline Rioja & & 1 & 1 & & 2 & 4,9 \\
\hline Andalucía & & & 1 & & 1 & 2,4 \\
\hline Aragón & & & 1 & & 1 & 2,4 \\
\hline Cantabria & & & 1 & & 1 & 2,4 \\
\hline TOTAL & 1 & 14 & 20 & 6 & 41 & 100 \\
\hline
\end{tabular}

Como ocurría con los canónigos, también en este caso se puede asociar la presencia de dignidades forasteras a un prelado concreto. Entre 1633 y 1649 ocupó la sede episcopal leonesa D. Bartolomé Santos de Risoba y ligados a este apellido y a los de Santos San Pedro, arzobispo de Granada y tío del anterior, nos encontramos a cuatro dignidades desde 1635 hasta 1687: D. Toribio Santos Risoba (1635), D. José Díez Santos de San Pedro (1660), D. Gregorio Ramos de Risoba (1667) y D. Pedro Ramos Martínez (1687), sobrino del anterior. Salvo el segundo, que fue abad de San Guillermo, el resto ocuparon el arcedianato de Saldaña, territorio del cual eran oriundos. Por el mismo también pasaron los sobrinos del obispo Aparicio: D. José Aparicio Núñez, quien más tarde pasó a la mitra astorgana, y D. Pedro Martínez de Aparicio. Por su parte, D. José Martínez de Aparicio llegó a ser abad de San Guillermo y Chantre; D. Miguel Martínez, alcanzó el priorato y D. Pedro Manuel, que al igual que gran parte de su parentela entró como canónigo, en el testamento de su tío, D. José, aparece como coadjutor a aquella dignidad e inquisidor de Murcia.

\section{LA CARRERA EN EL CABILDO}

En el libro Recésit se iban anotando todos los acontecimientos en la evolución profesional de los canónigos, desde su entrada hasta su fallecimiento. El que 
hemos manejado nosotros, y como ya hemos señalado, abarca desde 1680 hasta los inicios de la década de los treinta del siglo XIX, por lo que, en cierta medida, limita las ambiciones de nuestro trabajo, a lo que habría que añadir que deja al descubierto gran parte de las expectativas que pudiéramos tener en él, pues fueron muy parcos en las anotaciones. No obstante, nos ha permitido conocer, entre otras cuestiones, el periodo medio de ocupación de una canonjía. Se situó aquel en algo más de 25 años $^{46}$. En los extremos tenemos el 16,9\%, que tuvieron la desgracia de fallecer en los primeros diez años - de los cuales algo más de la mitad lo hicieron en el primer quinqueniocomo prebendados y el 16,1\% que llegó a estar más de 40. Por el contrario, si lo que pretendemos es analizar es la evolución de la carrera eclesiástica, la parquedad del citado libro nos limita mucho este objetivo. Entre los ascensos o traslados que no se anotaron estuvieron, por ejemplo, la promoción del canónigo D. Antonio Horcasitas al obispado de Calahorra, en 1715, o la partida de D. Manuel Martínez Aparicio a Granada, para ocupar el puesto de inquisidor en aquella ciudad.

Ciñéndonos a los datos disponibles en el libro de tabla, en el que se recogen un total de 283 canónigos, dignidades y oficios, para un $67,4 \%$ tan solo aparece la fecha de defunción, por lo que podríamos suponer que su carrera eclesiástica fue estable y en 4 ocasiones, es decir, en el 1,4\%, en unas circunstancias políticas de inestabilidad, aparece la anulación del nombramiento. Por lo tanto, solamente tenemos conocimiento del traslado o promoción a otros puestos de algo menos de un tercio. De éstos, la mayor parte, en torno al $60 \%$, ascendió dentro del propio cabildo y casi el $40 \%$ (lo que supone un $14,4 \%$ del total) salió hacia otros destinos, en algunos casos a ocupar canonjías en otros cabildos, ya fueran de mayor prestigio, como los de Toledo, Sevilla o Santiago, o porque estuvieran más próximos a su lugar de origen, lo que no implica que no fueran también más importantes. A este grupo pertenecerían D. Fernando Hermoso Díaz, natural de Fregenal, que se fue a Coria, D. Agustín Verjes Aragues, de Jaca, que partió a Zaragoza o los barceloneses D. Fernando Diern y D. Miguel Rius Tord, cuyos destinos fueron Gerona y Barcelona, respectivamente. Excepto D. Miguel Rius Tord, que había sido tesorero, el resto no habían ocupado puestos de relevancia. Prácticamente lo mismo podemos decir de los que pasaron a desempeñar dignidades u otros puestos más relevantes, caso, por ejemplo, de D. Juan Francisco Escando Noriega, quien era canónigo cuando fue nombrado Abad de Covadonga o D. José Vega Tincado, nombrado Deán en Lugo. Por lo que respecta a los que fueron promovidos a un obispado, solamente D. Rodrigo Valdés Busto dio el paso de canónigo a prelado; el resto ya habían ingresado en el cabildo leonés ocupando algún oficio o dignidad. Finalmente, y en lo que respecta a los que se trasladaron a ocupar un oficio en otro destino, prácticamente todos ellos ya los estaban ejerciendo en León, salvo D. Bernardo Froilán Saavedra Sanjurjo, quien

46 El libro Recésit nos proporcionó la fecha de entrada y fallecimiento de 238 miembros del cabildo, lo que nos ha permitido calcular la permanencia media en una canonjía, que fue de 25,8 años entre 1680 y 1749 . Se trató, pues, de una duración superior a la de los aragoneses, entre 14 y 17 años. Latorre Ciria 2009: 551. antes de ir como doctoral a Toledo había sido abad de San Guillermo en León (cuadro nำ7).

Si nos centramos en los que no se movieron del cabildo leonés, uno de los primeros pasos en la carrera era el ascenso de coadjutor a canónigo, para aquellos que no habían podido evitar ese nivel intermedio ${ }^{47}$ que suponía reforzar la patrimonialización de las canonjías y de las redes clientelares. ${ }^{48}$ Aquellos tenían que esperar la promoción una media era de 7,5 años, cifra que casi de dobla si introducimos casos como el de D. Martín Machado, para quien se demoró algo más de 20 años, tiempo que tardó en fallecer el titular del canonicato al que aspiraba. Más elevada era la espera para aquellos que dieron el salto desde una canonjía a uno de los cinco arcedianatos, unos 13,6 años, pero como ya sabemos algunos no necesitaron realizar ese paso intermedio. Una vez llegados a aquel escalafón, salvo casos excepcionales, como, por ejemplo, el de D. José Delgado Cuadrillero, que llegó a ser chantre, parece que la promoción se estancaba.

CUADRO № 7

Ascensos y traslados en el cabildo de la catedral de León entre 1680 y principios del siglo XIX

\begin{tabular}{|l|r|l|}
\hline Nuevos puestos & № & \multicolumn{1}{|c|}{ Destino } \\
\hline Obispos & 5 & $\begin{array}{l}\text { Badajoz, Cuenta, Teruel, Tarazona, } \\
\text { Calahorra y Guadix y Baza }\end{array}$ \\
\hline Oficios & 6 & $\begin{array}{l}\text { Doctoral: 3 (2 a Toledo y 1 Santiago) } \\
\text { Magistral: 2 (Granada y Sevilla) } \\
\text { Penitenciario: 1 (Santiago) }\end{array}$ \\
\hline Dignidades & 5 & $\begin{array}{l}\text { Deán: 3 (Lugo, Gerona y Palencia) } \\
\text { Abad de Covadonga } \\
\text { Abad de Santo Domingo de la Calzada }\end{array}$ \\
\hline Canónigos & 11 & $\begin{array}{l}\text { Badajoz: 1; Coria: 1; Sevilla: 1, Toledo: } \\
\text { desconocido: 1 }\end{array}$ \\
\hline Prior & 1 & Oviedo \\
\hline Fiscal de la Rota & 1 & Santiago: 1; \\
\hline Maestro Capilla & 1 & Granada \\
\hline Traslados & 5 & $\begin{array}{l}\text { Málaga, Calahorra, Barcelona, } \\
\text { desconocidos: 2 }\end{array}$ \\
\hline Beneficiado & 2 & Diócesis de Santiago y Valle \\
\hline
\end{tabular}

Como cabría esperar, son numerosos los casos en los que existía alguna relación entre el coadjutor y el titular de la canonjía a la que aspiraba, aunque es difícil trasladar su alcance a porcentajes. Esa dificultad se debe a que, a pesar de que en los expedientes de limpieza suelen recurrir a nombrar a otros miembros de la familia que estaban en activo o ya habían fallecido, en este u otro cabildo, para reforzar la condición de cristianos viejos, no suelen señalar el grado de parentesco que unía al candidato con aquellos. Podría solventarse ese obstáculo si

47 En Córdoba el ingreso por el sistema de coadjutorías supuso un $37 \%$ entre 1564 y 1753. Vázquez Lesmes 1987: 71-45. Sobre la elección de coadjutor y motivos consultar Irigoyen López 2000: 59-64.

48 Díaz Rodríguez 2009a: 287-309; Díaz Rodríguez y López-Salazar Codes 2014: 45-55; Morgado García 2000: 81. 
fuera factible reconstruir sus genealogías, pero el juego de apellidos nos dificulta poder realizar los encajes con toda solvencia. No obstante, hay suficientes casos que apoyan esos parentescos. ${ }^{49}$ Por ejemplo, D. Francisco Fuentes aspiraba a la de su tío, D. Isidro Fuentes, o D. Pedro Viguera, quien entró como coadjutor de su tío-abuelo D. Baltasar García de Aplicanos. Por su parte, a D. Mateo Manso Monroy, de la ciudad de Toro, quien formaba parte de un linaje que detentaba numerosos cargos esparcidos por diferentes puestos de la administración civil y eclesiástica, no se resultaría complicado conocer cuál era el momento más oportuno para presentarse a una vacante, o potencial vacante, en el cabildo leonés, del que formaban parte dos hermanos de su madre. De hecho, el mismo año que realizó el expediente para desempeñar el arcediano de Benamariel falleció su titular. Pero además de esos lazos de parentesco habría otros que emanaban de las relaciones entre familias, ya fueran sociales, profesionales o de otro tipo. ${ }^{50}$

Llegar a ocupar una plaza en el cabildo exigía cierta formación, aún más si se aspiraba a ascender en el organigrama eclesiástico. No ha sido muy numerosa la cifra de los canónigos que hemos encontrado en los listados de colegiales que han sido publicados de las universidades de Alcalá, Valladolid o Salamanca, tampoco la de los que hacen alusión al paso por esos centros, ya sea en los expedientes de limpieza o en los testamentos, pues cuando redactaban sus últimas voluntades después del nombre añadían su condición de colegial en el centro en que se habían formado. Así pues, todo parece indicar que la gran mayoría la única formación que tenían en el momento que dieron el primer paso para ocupar la canonjía era la correspondiente a clérigos de menores, tal y como señalaron en la primera parte de sus expedientes. Si bien no hemos de olvidar que a las que eran de oficio se accedía por oposición y los candidatos tenían que estar en posesión del título universitario correspondiente.

Respecto a los que poseemos datos sobre la formación académica y de su paso por un centro universitario, es complicado hacer una seriación y más aún del grado de estudios alcanzado. Los que hemos llegado a conocer, bien porque se recogen en las fuentes señaladas o por el cruce

\footnotetext{
49 Cabeza Rodríguez 1996.

50 D. Francisco Biergol Badillo hizo la limpieza de sangre, para maestreescuela, en 1715, si bien en 1714 aparece su nombramiento real como Arcediano de Saldaña, tras ser promovido, por el rey, su ocupante, D. Antonio de Horcasitas, al Obispado de Calahorra. No obstante, la Gaceta de Madrid, sitúa esos nombramientos en noviembre de 1714 Bien, pues en 1724 se inició el proceso para que entrara como coadjutor a ese arcedianato D. Enrique de Ulloa, hijo del señor de la villa de Doncos y su jurisdicción, D. Pedro Ulloa Miranda y Rivadeneira, por cuanto «D. Juan Francisco Biergol Boadillo, caballero de la orden de Santiago, arcediano de Saldaña y canónigo de la Santa Iglesia catedral de esta ciudad, ha dado y otorgado poder cumplido y en forma pidiendo y suplicando a su santidad, por causas que a ello le mueven sea diputado por coadjutor perpetuo e irrevocable con futura sucesión de dicha dignidad y canonicato, el señor D. Enrique Ulloa, clérigo de menores órdenes». No sabemos si existía alguna relación de parentesco entre esa dignidad y su coadjutor, pero sí parece que la había entre el padre del candidato y D. José Ribadeneira Saavedra, regidor perpetuo de León, que fue quien representó en esta ciudad a los señores de Ulloa. En 1725 se hizo la limpieza de sangre de D. Enrique y dos años después falleció D. Juan Francisco. A.H.D.L. Protocolos notariales.
}

con los listados de colegiales ${ }^{51}$, el abanico de instituciones es muy amplio y, por supuesto, está relacionado con su lugar de origen. Hubo alumnos de los colegios de Oviedo, San Bartolomé y el de Cuenca, de la Universidad de Salamanca; de los de San Idelfonso y San Ciriaco y Santa Paula, en Alcalá de Henares; La Anunciada, de Murcia; Santa Cruz, de Valladolid o la Universidad de Sevilla. Pero, a la luz de los datos recabados, parece que, en general, lo que predominó fue una educación más básica. Los leoneses, y antes de que el seminario de San Froilán abriera sus puertas, realizaron sus estudios en las cátedras que poseían los conventos de la ciudad.52 Algunos, a continuación, pasaron a completar su formación en Roma ${ }^{53}$, caso de D. Javier Gutiérrez o D. Marcelino Escobar. También por la corte romana, destino perfecto para lograr alcanzar los favores de la curia de cara a la obtención de una bula que les diera acceso al cabildo, habían pasado algunos de los forasteros..$^{54}$ Otros fueron ampliado experiencia a la sombra de un prelado, D. Miguel Lagartos se formó con D. Antonio Horcasitas, canónigo leonés que fue nombrado obispo de Calahorra en 1715; los hermanos D. Diego y Joaquín Villafañe lo hicieron con su tío, D. José Flórez, obispo de Orihuela, o D. Esteban María Cruzado, quien, después de realizar sus estudios, pasó a servir al obispo de León, desde donde alcanzó el canonicato.

LOS CANÓNIGOS LEONESES A MEDIADOS DEL SIGLO XVIII: FORMAS DE CORRESIDENCIA

El libro de familia del catastro del marqués de la Ensenada recoge 56 miembros del cabildo catedralito: 11 ostentaban dignidades, 4 oficios, 37 eran prebendados y 4 coadjutores. La radiografía que obtenemos en ese momento concreto, nos muestra una edad media de $48 \operatorname{años}^{55}$ y habían hecho las pruebas de limpieza sobre los $29^{56}$, por lo que podemos

51 Carabias Torres 1985: 86-105 y 1991: 43-88; Carabias Torres, Benito Rodríguez, Carrasco Mateos y Pérez Paniagua 1990: 183-265; Fernández Catón 1960: 259-329; Gutiérrez Torrecilla 1992; Sobaler Seco 2000. Otras instituciones muy relacionadas con León fueron el colegio de San Clemente, en Bolonia, o San Justo, en Sigüenza, en los que el cabildo controlaba alguna de las becas que en ellos se ofrecían. Martín García 2012: 139.

52 Ibídem: 139-140.

53 « pertenecer al clero capitular era, sin lugar a dudas, una inversión segura». García Pérez 2014.

54 Tal y como ha señalado Iglesias Ortega - hay una relación directa entre la institución a la que se sirve y la que designa- (2012b: 153).

55 Más próxima a la constada por Irigoyen López (2000) a finales del siglo XVI para el cabildo murciano -40 años - que la de los aragoneses en el último tercio del siglo XVIII. Latorre Ciria 2009: 551.

56 La edad sube dos años si mantenemos a los tres que venían de ocupar otros puestos. Se trataba de Santiago Baizán Avecilla, que había sido capellán del rey en Aranjuez, además de párroco de algunas localidades, que hizo las pruebas, para canónigo por vacante de D. Pedro Robles, con 50 años; la mima que tenía D. Cristóbal Fernández de Villalba - provisor y vicario del obispado, rector del seminario y abogado de los reales consejos- cuando accedió a la que dejó D. Sebastián Montegayoso; más joven era D. Juan Martínez Matute, 42 años, antes abogado de los reales consejos, quién ocupó la canonjía que había pertenecido a D. Juan Montegayoso, hermano del anterior. Por otro lado, si tenemos en cuenta que no todos entraban directamente a ocupar una canonjía, y, como coadjutores, debían de esperar una media de algo más de siete años, se puede decir que el porcentaje de los que recibieron esa prebenda antes de los 40 años fue muy elevado, lo cual queda ratificado por la media de edad que tenían los que estaban en activo a mediados del siglo XVIII. 
decir, en conjunto, que se trataba de un grupo con cierta veteranía. Ahora bien, hemos de tener presente que, dado lo limitado de la muestra, los casos extremos distorsionan el cálculo. Si eliminamos aquellos observamos que la realidad era otra: aumenta la veteranía y, en consonancia, las expectativas de reemplazo. De hecho, si la media global de permanencia en una canonjía era de 25 años, en este momento se situaba en los 19, es decir, en conjunto ya habían recorrido tres cuartas partes de su carrera. A lo que hemos de añadir que un porcentaje similar superaba los 43 años. Si bien la renovación más inmediata, teniendo en cuenta que la muerte les llegaba en torno a los 62 años, afectaba a un $9,6 \%$, que eran quienes la superaban y teóricamente tenían mayores posibilidades de dejar paso al ingreso de nuevas generaciones. Por supuesto, ese porcentaje está ajustado a las medias y en él no computan variables tan directas como la enfermedad o mortandad.

De aquellos 56 capitulares, 3 se hallaban ausentes ${ }^{57}$ y de los que permanecían en la ciudad, 3 vivían en el obispado ${ }^{58}$, 1 en el seminario ${ }^{59}, 3$ en la residencia familiar $^{60}$ y siete con otros canónigos -3 con un tío, 2 con un hermano y otros dos no sabemos la relación que le unía con el titular del hogar-. ${ }^{61}$ Así pues, de los presentes en León eran $39(69,6 \%)$ los que mantenían casa abierta. El compartir morada no resultaba inhabitual, por ejemplo, en 1724, D. José Martínez de Aparicio, chantre en ese momento, y su hermano, por parte de padre, D. Miguel Martínez de Rodrigo, decidieron disolver su comunidad de bienes, tras treinta años de convivencia, para evitar que entre sus herederos pudieran plantearse litigios por no estar clara la titularidad de aquellos. Hasta entonces habían mantenido el sistema de gananciales «celosos del aumento y conservación de sus casas y familia». ${ }^{62}$

Respecto a uno de los canónigos que vivía en la casa familiar, D. Diego Villafañe, el problema de residencia se le planteó cuando su hermano mayor decidió reorganizar el patrimonio. ${ }^{63}$ En 1771, el heredero del mayorazgo, D. José,

57 Se trataba de D. José Porras Bustillo, D. Manuel de Terrazas Vargas y D. Carlos Espinós Pi. Por el primero hizo declaración D. José Celayeta, pero simplemente dejó constancia de su ausencia, no debió de volver a León y falleció en 1754 en Palencia. Tampoco D. Manuel, en Madrid en ese momento, debió regresar a León, pues en 1753 se dio posesión de su canonicato a su coadjutor, D. Pedro Ribadeneyra, que vivía en casa de su padre. Finalmente, la relación de D. Carlos, que no tardó en regresar, la hizo su compañero de residencia, D. Marcos Rodríguez, dijo que tenía dos criadas y un paje y era él quien los cuidaba.

58 D. Manuel de los Ríos, en calidad de mayordomo, D. Fernando Feijó, como su secretario de cámara y no sabernos el puesto que desempeñaba D. Esteban Cruzado.

59 Se trataba de D. Cristóbal Fernández, rector del seminario y provisor y vicario del obispado.

60 Los hermanos D. Joaquín y D. Diego, ambos canónigos, vivían en casa de su madre, Dña. Catalina Flórez Osorio; y D. Pedro Ribadeneyra, aún coadjutor, lo hacía en la de su padre, regidor de la ciudad.

61 Con D. Diego Viguera Escudero vivía su sobrino, D. Pedro Alenson Viguera, y D. Manuel Díaz Santos Gullón lo hacía con su tío, D. Diego Manuel, Chantre; juntos residían los hermanos Almirante, D. Francisco y D. Alonso, y los Lagartos, D. Miguel y D. Juan, y con los últimos compartía morada D. Francisco Luis Alberni, aunque pare que iba a ser algo transitorio, pues, como señalaban, "está recién llegado» — su limpieza de sangre se había hecho el año anterior-.

62 A.H.D.L. Protocolos Notariales.

63 Si eliminamos de este cálculo a los que vivían en el seminario u obispado y nos ceñimos a los que se alojaban en el hogar familiar, coronel del regimiento de milicias del reino de León, solicitó el reparto de la herencia y pidió a los dos hermanos que aún residían en el hogar, D. Diego y D. Juan, clérigo de menores, que lo abandonaran. ${ }^{64}$ Los afectados le respondían que estaban viviendo en ella "por espacio de treinta y cinco años y cuatro meses en los cuartos altos de la casa común que en esta ciudad les dejó señalados su difunto padre, independientes de las habitaciones que tiene dicha casa para personas seglares». No llegaron a ningún acuerdo e iniciaron un proceso judicial. ${ }^{65}$

En aquellos 39 hogares encabezados por capitulares, vivían 208 personas, lo que arroja una media de 5,366, si bien hemos de tener en cuenta que un $40 \%$ de los mismos superaban las seis personas. El grupo más numeroso era el formado por personal de servicio, que suponía el 60,6\%, seguido de los canónigos, 23,6\%, parientes, $12,5 \%$ y, el genérico, otras personas, $3,4 \%$ (cuadro no 8). Comenzado por los parientes, 15 miembros del cabildo catedralicio $(38,5 \%)$ tenían a su cargo a algún familiar, todos de líneas colaterales o descendentes. Los más frecuentes eran los sobrinos, sobrinas, hermanas, una de ellas viuda, primas y hermanos. Algunos de esos sobrinos estaba estudiando la carrera eclesiástica y otros se estarían formando a la sombra del canónigo. Por lo que respecta a la parentela femenina, es probable que hubiera un doble escalafón, mientras las más próximas en grado de consanguineidad podrían ejercer labores de dirección en el hogar, e incluso utilizar ese amparo y protección como plataforma para un buen enlace matrimonial; otras tendrían un papel menos privilegiado, casi equiparable al del personal de servicio. De hecho, aunque la diferencia es muy pequeña, podemos comprobar cómo en los hogares en que había mujeres la media de criadas era de 1,4, frente a 1,8 en el resto. Bajo el genérico "otros» hemos incluido a los capellanes y otros sobrinos a los que dicen asistir pero cuyas circunstancias son diferentes a las de los anteriores, pues ya estaban trabajando, alguno fuera de esa ciudad. El que bajo la tutela de los canónigos se agrupara un conjunto tan variado de personas es lo que condujo a que solamente un $25 \%$ de sus hogares estuvieran formados por sus titulares y el servicio doméstico. ${ }^{67}$

comprobamos como los canónigos leoneses eran más independientes que los de Burgos, donde el 13,8\% residía en casa de algún pariente. Sanz de la Higuera 2007: 570.

64 D. Joaquín, hermano de ellos y también canónigo ya no convivía con aquellos.

65 A.H.D.L. Protocolos Notariales.

66 El servicio doméstico era más numeroso en Santiago, 4,7 personas por unidad doméstica frente a 3 en León. Este dato repercutiría considerablemente en la media global, pues mientras en León era de 5,3 en Santiago era de 7,1, cifra muy próxima a la murciana. Los resultados leoneses se identificaría más con los hogares de los canónigos burgaleses, 4,7 . En León, el libro de familia del catastro del marqués de la Ensenada no nos ofrece datos sobre el número de personas alojadas en el palacio episcopal. Dubert García 1987: 34; Irigoyen López 2010: 312; Sanz de la Higuera 2006: 55.

67 Se trata de un porcentaje muy alejado del que reflejan las diócesis gallegas para las mismas fechas. Rey Castelao 1990: 594. 
CUADRO № 8

Corresidencia en los hogares de los canónigos leoneses a mediados del siglo XVIII

\begin{tabular}{|c|c|c|c|c|c|c|c|c|c|c|}
\hline \multirow[b]{3}{*}{ Canónigos } & \multirow{3}{*}{$\begin{array}{l}\text { № } \\
49\end{array}$} & \multirow{3}{*}{$\begin{array}{c}\% \\
23,6\end{array}$} & \multirow{3}{*}{$\begin{array}{c}\text { Media } \\
1,2-2,2^{*}\end{array}$} & \multicolumn{7}{|c|}{ Sexo del personal de servicio } \\
\hline & & & & \multicolumn{3}{|c|}{ Total } & \multicolumn{2}{|c|}{$\begin{array}{l}\text { Dignidades y } \\
\text { oficios }\end{array}$} & \multicolumn{2}{|c|}{ Canónigos } \\
\hline & & & & & № & $\%$ & № & $\%$ & № & $\%$ \\
\hline \multirow{2}{*}{ Personal de servicio } & \multirow{2}{*}{126} & \multirow{2}{*}{60,6} & \multirow{2}{*}{3} & Mujeres & 75 & 59,5 & 16 & 44,4 & 59 & 65,6 \\
\hline & & & & Varones & 51 & 40,5 & 20 & 55,6 & 31 & 34,4 \\
\hline Otros & 7 & 3,4 & 1,2 & & & & & & & \\
\hline Parientes & 26 & 12,5 & 1,6 & & & & & & & \\
\hline TOTAL & 208 & 100 & 5,3 & & & & & & & \\
\hline
\end{tabular}

*1,2 global y 2,2 en 6 hogares en los que vivían más de un canónigo.

Todos los hogares tenían doméstico y la media de asistentes coincidió con el valor modal: 3 trabajadores por casa. ${ }^{68}$ Si bien alguna, como la del Arcediano de Saldaña llegó a tener 7 personas a su servicio. El peso femenino fue más acusado que el masculino. Amas y criadas representaban el 59,5 frente a 40,5 criados. ${ }^{69}$ Ahora bien, ese personal estaba más masculinizado en los hogares regentados por dignidades $u$ oficios, que arrojaban una media de 2,3 criados, que en la de los simples canónigos, donde se quedaba en 1 . Esa diferencia reside en que los primeros eran más aficionados a tener servidumbre especializada que dieran realce social al hogar, como lacayos, algún mayordomo o cochero..$^{70}$ Por otro lado, dentro de este colectivo tenemos que diferenciar entre pajes y criados. Los primeros, todos estudiantes, representaban un $72,5 \%$ e, incluso, alguno de los considerados criados también estaban estudiando. Es de suponer que entre educandos y tutores no existían lazos de parentesco próximos, pues sino, como en el caso de los sobrinos que se estaban formando, quedarían reflejados.

La media de mujeres que asistía a canónigos era de 2,1 , pocos superaban las tres y solo el deán y un arcediano tenían en su casa a 4 sirvientas. En algunas ocasiones, las menos, había una jerarquía entre ellas, ama y criada o bien criada mayor y criada menor o de cocina, si bien estas precisiones, que en algunos testamentos son muy claras, no se reflejan con la misma nitidez en los libros de familia. Esa jerarquía no solo se evidenciaba en el grado de responsabilidad que les correspondía dentro del hogar y en los salarios, también solía ponerse de manifiesto en las mandas testamentarias, en las que les reconocían la

68 La media de personal de servicio de este colectivo es más baja que la murciana, donde había 4 y el peso de uno y otro sexo era equiparable, y se aproxima más a la de algunas ciudades gallegas - caso de Lugo, con 3, u Orense con 2,5- y Burgos, 3,2 sirvientes en las residencias de las dignidades y 2,1 en las de los canónigos. En León esas cifras eran 3,4 y 2,7, respectivamente. Irigoyen López 2010: 317; Rey Castelao 1990: 593; Sanz de la Higuera 2006: 550.

69 Una masculinización en el servicio doméstico más baja que la observada en el cabildo de burgos, pero que coincide en lo que respecta a más varones en los escalafones más elevados. Ibídem: 552.

70 Eiras Roel 1984: 121-122; Irigoyen López 2010: 322. fidelidad con la que habían desempeñado su trabajo. ${ }^{71}$ Así mismo, aunque no abundantes, son los casos de criadas cuyo nombre va precedido de doña o son originarias de la misma demarcación territorial que el canónigo. El deán D. Fernando de Navia, procuró un buen matrimonio a Dña. Joaquina Fernández, asturiana al igual que él, con D. José Martínez de Lerma, procurador en León y hermano del mayordomo del abad de San Isidoro, y además la dotó 1.000 ducados, pagaderos en 10 años - «por los buenos servicios que le ha hecho Dña. Joaquina y otra circunstancias»-. Posiblemente, esta mujer, aun formando parte del servicio, tuviera algún tipo de relación familiar con el canónigo.

Por otro lado, es relativamente frecuente localizar algún tipo de parentesco entre las criadas -el de hermanas o tía y sobrina son los que con mayor frecuencia quedaron reflejados-, pero posiblemente hubiera otras relaciones, ya fueran familiares con un grado de consanguineidad más alejado, o derivaran del lugar de procedencia. Pero volviendo a lo que hemos señalado anteriormente, algunos de estos hombres tenían mujeres de la familia que podían colaborar en la administración del hogar. Por supuesto el nivel de unas y otras no sería el mismo, pues mientras las hermanas gozarían de un puesto privilegiado, las primas quizá estarían a un nivel muy similar al de las criadas. Si bien esta afirmación puede ser matizable. D. Anselmo López Barrio compartía morada con una criada, un paje, un estudiante de moral y una prima carnal, Dña. Manuela. Quizá esa fuera una salida natural, honorable y con perspectivas de un buen enlace matrimonial para una mujer huérfana, cuyos hermanos vivían en Asturias y Cartagena. ${ }^{72}$

71 El canónigo D. Juan de Vega pagaba a una de sus criadas, María Santos, 15 reales cada mes y le mandó una serie de bienes, entre los cuales, y muy frecuente, estaba la cama en que dormía con todo el ajuar con el que estaba equipada y algunos muebles; en cambio, a la otra, Josefa Rabanal, cuyo salario era un tercio inferior, aunque también tuvo alguna deferencia con ella no estuvo ni próxima al nivel de la que recibió su compañera. A.H.D.L. Protocolos Notariales.

72 Se trataba de una hermana casada y un hermano soltero, D. Juan. Cuando este falleció en Cartagena, en 1764, las dejó herederas de un patrimonio que, según señalaban, era importante. A.H.D.L. Protocolos Notariales. 


\section{CONCLUSIONES}

Los expedientes de limpieza de sangre, complementados con protocolos eclesiásticos o el libro Récesit, nos han permitido acercarnos a los miembros del cabildo catedralicio leonés y trazar un pequeña evolución cuantitativa, así como de la procedencia social de sus integrantes. El número de canónigos leoneses, al igual que en otras ciudades, fue descendiendo a lo largo de la Edad Moderna, de forma paralela a la pérdida de valor de las prebendas. En común, con otros ya estudiados, en el leonés también podremos comprobar cómo, salvo en cuestiones puntuales, las bolsas de reclutamiento y formas de acceso tampoco difieren mucho, en lo que se respecta al grupo social al que pertenecían o los lazos de endogamia familiar y geográfica que se desarrollaron, en algunos casos enlazada con el nombramiento de un nuevo obispo. Aparentemente, no se trataba de canónigos con una gran formación intelectual y si la habían adquirido no parece que hubiera sido en las universidades. Finalmente, el libro de familia del catastro del marqués de la Ensenada, nos ha aportado, datos puntuales, sobre las unidades domésticas, tales como las formas de corresidencia, si acogían o no familiares, o el servicio doméstico. Así mismo, esta misma fuente, realizando los pertinentes cruces con otra documentación eclesiástica, ya señalada, nos ha proporcionado información demográfica, como el envejecimiento de los capitulares en ese momento concreto.

\section{BibLIOGRAFÍA}

Cabeza Rodríguez, A. 1996. Clérigos y señores. Política y religión en Palencia en el Siglo de Oro. Palencia: Diputación de Palencia.

Cabeza Rodríguez, A. 2000. "Entre mayorazgos y capillas. La oligarquía eclesiástica de Palencia en el siglo XVI»), en F. J. Aranda Pérez (coord.), Sociedad y élites eclesiásticas en la España moderna: 35-46. Cuenca: Universidad de Castilla-La Mancha.

Callado Estela, E. 2001. Iglesia, poder y sociedad en el siglo XVII. EI arzobispo fray Isidoro Aliaga. Valencia: Generalitat Valenciana.

Callado Estela, E. 2011. «El Patriarca Ribera y el clero catedralicio valentino», en E. Callado Estela (coord.), Lux totius Hispanie. El Patriarca Ribera cuatrocientos años después II: 337-370. Valencia: Universitat de Valencia.

Carabias Torres, A. M. 1985. «Catálogo de colegiales del Colegio Mayor de Oviedo (Siglo XVI)». Studia Histórica. Historia Moderna 3: 86-105.

Carabias Torres, A. M. 1991. "Catálogo de colegiales del Colegio Mayor de San Bartolomé (1700-1840)». Studia Histórica. Historia Moderna 9: 43-88.

Carabias Torres, A. M., Benito Rodríguez, M. A., Carrasco Mateos, M. y Pérez Paniagua, M. A. 1990. «Catálogo de colegiales del Colegio Mayor de San Bartolomé en el Siglo XVII». Studia Histórica. Historia Moderna 8: 183-265.

Carasa Soto, P. 1993. Censo Ensenada, 1756. Madrid: Tabapress.

Casado Casado, H. 1980. La propiedad eclesiástica en la diócesis de Burgos en el siglo XV: el cabildo catedralicio. Valladolid: Universidad de Valladolid.

Castillón Cortada, F. 1990. "Estructura del cabildo catedralicio de Lleida durante el siglo XVIII», en Eglésia i societat a la Catalunya del segle XVIII: 99-117. Cervera: UNED.

Chaubel I Cabrera, M. A. 1999. "L'extracció social i geogràfica de la clerecia lleidatana del Set-cents», en Historia moderna, historia en construcción. Sociedad, Política e Instituciones: vol. II, 55-70. Lleida: Editorial Milenio.

Coronas Vida, L. J. 1986. "Los miembros del cabildo de la catedral de Jaén (1700-1737)». Chronica Nova 18: 101-126.
Delille, G. 2015. El alcalde y el cura. Poder central y poder local en el Mediterráneo occidental. Siglos XVI-XVIII. Murcia: Universidad de Murcia.

Díaz Rodríguez, A. J. 2009a. «El precio del nepotismo. Coadjutoría y resigna en las catedrales andaluzas (SS. XVI-XVIII)». Chronica Nova 35: 287-309.

Díaz Rodríguez, A. J. 2009b. «Entre parientes. Modelos de formación de dinastías en el cabildo catedralicio cordobés (ss. XVI-XVIII)", en E. Soria Mesa, J. J. Bravo Caro y J. M. Delgado Barrado (coords.), Congreso internacional "Las élites en la época moderna: la monarquía española»: vol. II, 161-174. Córdoba: Universidad de Córdoba.

Díaz Rodríguez, A. J. y López-Salazar Codes, A. I. 2014. «El cabildo catedralicio de Évora en la Edad Moderna (1547-1801)». Historia y Genealogía 4: 31-57.

Dubert García, I. 1987. Los comportamientos de la familia urbana en la Galicia del Antiguo Régimen. El ejemplo de Santiago de Compostela en el siglo XVIII. Santiago: Universidade de Santiago de Compostela.

Egido López, T. 2000. «El cabildo de Valladolid. Conflictos jurisdiccionales», en F. J. Aranda Pérez (coord.), Sociedad y élites eclesiásticas en la España moderna: 21-34. Cuenca: Universidad de Castilla-La Mancha.

Eiras Roel, A. 1984. "Las élites urbanas de una ciudad tradicional: Santiago de Compostela a mediados del siglo XVIII", en Actas del II Coloquio de Metodología Histórica Aplicada. La documentación notarial y la Historia: 121-122. Santiago de Compostela: Universidad de Santiago de Compostela.

Fatjó Gómez, P. 1993. "Aproximación a una élite institucional de la Catalunya moderna: los capitulares de la Seo de Barcelona en el siglo XVII». Pedralbes 13: 149-159.

Fernández Catón, J. M. 1960. «El Colegio Mayor de San Salvador de Oviedo de la Universidad de Salamanca». Studium Legionense 1: 259-329.

Fernández Collado, A. 2000. «Grupos de poder en el cabildo toledano del siglo XVI», en F. J. Aranda Pérez (coord.), Sociedad y élites eclesiásticas en la España moderna: 71-100. Cuenca: Universidad de Castilla-La Mancha.

Fernández Conde, M. 1948. España y los seminarios tridentinos. Madrid: CSIC/Instituto «Enrique Flórez».

Fernández Del Pozo, J. M. 2004. "Las rentas de la mesa capitular de la Iglesia de León y su evolución. Siglos XV-XVIII», en Escritos dedicados a José María Fernández Catón: 345-475. León: Centro de Estudios e Investigación «San Isidoro».

Fernández Díaz, R. 1990. "La clerecía catalana en el Setecientos», en Esglesia i societat a la Catalunya del segle XVIII: vol. I, 23-118. Cervera: UNED.

Fernández Terricabras, I. 2000. Felipe II y el clero secular. La aplicación del Concilio de Trento. Madrid: Sociedad Estatal para la Conmemoración de los Centenarios de Felipe II y Carlos V.

García Oro, J. 2004. "La reforma tridentina en la Iglesia de León», en Escritos dedicados a José María Fernández Catón: 545-569. León: Centro de Estudios e Investigación "San Isidoro».

García Pérez, F. J. 2014. «El Cabildo catedralicio de Mallorca (17001750). Estudio de una élite de poder durante el siglo XVIII». Tiempos Modernos 29. [Texto electrónico].

García, M.a T., Nicolás, M. I. y Bautista, M. 1990. La propiedad urbana del Cabildo Catedral de León en el siglo XV. León: Institución Fray Bernardino de Sahagún.

Goñi Gaztambide, J. 1975. «Los cabildo españoles y la confirmación del Concilio de Trento». Annuarium Historiae Conciliorum 7: 425-458.

Gutiérrez Torrecilla, L. M. 1992. Catálogo biográfico de los colegiales y capellanes del Colegio Mayor de San Idelfonso de la Universidad de Alcalá (1508-1786). Alcalá de Henares: Universidad de Alcalá de Henares.

Hermann, C. 1982. «Iglesias y poder. El encuadramiento pastoral en el siglo XVIII». Cuaderno de Investigación Histórica 6: 149-151.

Iglesias Ortega, A. 2012a. «Un cabildo castellanizado: la procedencia geográfica de los capitulares compostelanos a comienzo del período moderno». Investigaciones históricas 32: 13-42. 
Iglesias Ortega, A. 2012b. «El curriculum vitae de los capitulares en el siglo XVI: el ejemplo del cabildo catedral de Santiago». Historia y Genealogía 2: 145-174.

Irigoyen López, A. 2000. Entre el cielo y la tierra, entre la familia y la institución. El cabildo de la catedral de Murcia en el siglo XVII. Murcia: Universidad de Murcia.

Irigoyen López, A. 2010. «Aproximación al estudio del servicio doméstico del alto clero de Murcia durante el siglo XVIII». Obradoiro Historia Moderna 19: 307-327.

Jiménez Sureda, M. 1999. L'Església catalana sota la monarquia dels Borbons. La catedral de Girona en el segle XVIII. Barcelona: Abadía de Monserrat.

Latorre Ciria, J. M. 2009. «Perfiles de un grupo eclesiástico: los canónigos aragoneses del último tercio del siglo XVIII». Hispania Sacra 124: 545-569.

López López, R. J. 2005. «Los cabildos catedralicios gallegos durante la Edad Moderna. Investigaciones de los últimos treinta años». Estudios Mindonienses 21: 547-584.

López López, R. J. 2010. «El cabildo y los canónigos de la catedral de Oviedo en la Edad Moderna. Un repaso por la historiografía reciente y una propuesta de investigación». Semata. Ciencias Sociais e Humanidades 22: 131-155.

Marín López, R. 1998. El cabildo de la catedral de Granada en el siglo XVI. Granada: Universidad de Granada.

Marín López, R. 2007. "Historiografía sobre cabildos eclesiásticos. Estado de la cuestión y perspectivas de investigación, en A. L. Cortés Peña y M. L. López-Guadalupe Muñoz (eds.), La Iglesia española en la Edad Moderna. Balance historiográfico y perspectivas: 75-112. Madrid: Abada Editores.

Martín García, A. 2012. "Reforma y educación clerical en la diócesis de León: el seminario de San Froilán (1606-1805)», en L. M. Rubio Pérez, Instituciones y centros de reclusión colectiva: formas y claves de una respuesta social (siglos XVI-XX): 131-156. León: Universidad de León.

Morgado García, A. 1989a. Iglesia y sociedad en el Cádiz del siglo XVIII. Cádiz: Universidad de Cádiz.

Morgado García, A. 1989b. El clero gaditano a fines del Antiguo Régimen. Cádiz: Fundación Municipal de Cultura del Excmo. Ayuntamiento de Cádiz.

Morgado García, A. 1990. "El clero gaditano en el siglo XVIII», en Coloquio Internacional Carlos III y su Siglo: 389-402. Madrid: Universidad Complutense de Madrid.

Morgado García, A. 2000. «Vida del canónigo. Percepción. Origen y status de vida del alto clero durante el antiguo régimen», en F. J. Aranda Pérez (coord.), Sociedad y élites eclesiásticas en la España moderna: 77-100. Cuenca: Universidad de Castilla-La Mancha.

Morgado García, A. 2006. «La iglesia como factor de movilidad social: las carreras eclesiásticas en la España del Antiguo Régimen», en F. Chacón Jiménez y N. G. Monteiro (eds.), Poder y movilidad social. Cortesanos, religiosos y oligarquías en la Península Ibérica (siglos $X V$-XIX): 61-92. Madrid: CSIC.

Morgado García, A. 2007. «El clero en la España de los siglos XVI y XVII. Estado de la cuestión y últimas tendencias». Manuscrits 25: 75-100.

Morgado García, A. 2008. La diócesis de Cádiz: desde Trento hasta la desamortización. Cádiz: Universidad de Cádiz.

Pérez Álvarez, M. J. 2016. «Curas y amancebadas: los pleitos ante el tribunal eclesiástico de la diócesis de León en el siglo XVIII». Historia et ius 9: 1-17.
Pérez López, S. 2000. "La diócesis de Mondoñedo en el siglo XVIII vista por sus obispos», en Congreso do Patrimonio da Diócesis de Mondoñedo: 13-78. Coruña: Universidade da Coruña.

Prieto Escanciano, E. 2004. «Dimensión docente del cabildo de la catedral de León», en J. Paniagua Pérez y F. Ramos (coords.), En torno a la Catedral de León: 241-250. León: Universidad de León.

Rey Castelao, O. 1990. "El clero gallego en tiempos de Carlos III», en Coloquio Internacional Carlos III y su Siglo: 579-600. Madrid: Universidad Complutense de Madrid.

Rey Castelao, O. 1996. "Edad Moderna: Iglesia y religión», en M. V. García Quintela (coord.), Las religiones en la historia de Galicia: 141-180. A Coruña: Universidade da Coruña.

Risco, M. 1787. La España Sagrada. Memorias de la Santa Iglesia exenta de León. Madrid: Fortanet.

Rodicio Pereira, L. 2013. "Ser canónigo en Ourense a finales del siglo XVIII». Diversarum rerum 8: 135-158.

Rubio Pérez, L. M. 1993. León 1751. Según las Respuestas Generales del Catastro de Ensenada. Madrid: Tabapress.

Rubio Pérez, L. M. 2013. «Párrocos, parroquias y concejos: el modelo parroquial leonés en el marco de las comunidades rurales y concejiles durante la Edad Moderna». Obradoiro 22: 129-166.

Sánchez González, R. 2000. Iglesia y sociedad en la Castilla Moderna: el cabildo catedralicio de la sede primada (siglo XVII). Cuenca: Universidad de Castilla-La Mancha.

Sánchez Herrero, J. 1995. "La iglesia y la religiosidad católica en Zamora durante la Edad Moderna: Siglos XVI y XVII», en Historia de Zamora: 413-461. Zamora: Diputación.

Sanz de la Higuera, F. J. 2006. "'En casa [,cama] y compañía'. Yacer a lomos del XVIII en los hogares eclesiásticos burgaleses». Hispania Sacra 118: 545-577.

Sanz de la Higuera, F. J. 2007. «Clérigos a la sombra de un pariente en el XVIII burgalés». Hispania Sacra 120: 563-594.

Sarmiento Pérez, J. 2005. Reforma beneficial en la diócesis de Badajoz durante la crisis del Antiguo Régimen (1769-1841). Badajoz: Diputación de Badajoz.

Sobaler Seco, M. A. 2000. Catálogo de colegiales del colegio mayor de Santa Cruz de Valladolid (1484-1786). Valladolid: Universidad de Valladolid.

Trujillo, F. 1926. La Iglesia de León. León: Imprenta Católica.

Vázquez Lesmes, J. R. 1983. Córdoba y su cabildo catedralicio. Córdoba.

Vázquez Lesmes, J. R. 1987. Córdoba y su cabildo en la modernidad. Córdoba: Cajasur.

Vázquez Lesmes, J. R. 1999. «El cabildo catedralicio cordobés en tiempo de Felipe II: limpieza de sangre y élite de poder», en J. L. Pereira Iglesias, J. M. Bernardo Ares y J. M. González Beltrán (coords.), Actas de la V Reunión Científica de la Asociación Española de Historia Moderna: 597-603. Cádiz: Universidad de Cádiz.

Vázquez Lesmes, J. R. 2008. «Participación y poder de la nobleza en la composición de un cabildo catedralicio. Córdoba, siglos XVII y XVIII», en J. L. Castellano y M. L. López-Guadalupe Muñoz (eds.), Homenaje a Don Antonio Domínguez Ortiz: 813-830. Granada: Universidad de Granada.

Villacorta Rodríguez, T. 1974. El cabildo de la catedral de León. Estudio Histórico-jurídico, siglos XII-XIX. León: Centro de Estudios e Investigación San Isidoro - Caja Ahorros Monte Piedad.

Villacorta Rodríguez, T. 2004. "Constitución y funcionamiento del Cabildo de la Catedral de León», en J. Paniagua Pérez y F. Ramos (coords.), En torno a la catedral de León: 199-220. León: Universidad de León. 